\title{
Schreibweise der nichtdeutschen Worte im Text.
}

Das russische :k, welches in der Aussprache dem französischen j entspricht, ist, wie jetzt vielfach gebräuchlich, durch sh wiedergegeben.

Das russische :, welches wie das deutsche s z. B. im Wort weisen ausgesprochen wird, ist durch $s$ wiedergegeben.

Das russische $c$, welches wie das deutsche $\beta$ ausgesprochen wird, ist durch ss bezw. B wiedergegeben. (Auf der Ubersichtskarte des Zentralen Tian-Schan sind nur die Namen russischen Ursprunges so geschrieben, im Text alle diejenigen nichtrussischen Namen, welche in russischen geographischen und linguistischen Werken und auf russischen Karten ein c führen.)

Das russische w, welches sich im Deutschen schwer wiedergeben läßt, wird am annäherndsten durch $i \mathrm{j}$ transkribiert. Das in russischen Biichern und auf russischen Karten in $\mathrm{nich}$ trussischen Namen vorkommende, ist durchgehends mit y oder ï wiedergegeben. In den Türk-Worten ist dieses y und ii wie das deutsche ii, resp. ö auszusprechen.

Das russische t: ist je nach dem einzelnen Fall durch je oder durch jä transkribiert. 

